\title{
One-Pot Synthesis of Aldol Adduct Catalyzed by Immobilized Picolylamine on Zirconia
}

\author{
Mohammad Sadiq, Razia, M. Naveed Umar, Gul Zamin \\ Department of Chemistry, University of Malakand, Khyber, Pakistan \\ Email:sadiq@uom.edu.pk, mohammad_sadiq26@yahoo.com
}

Received October 25, 2013; revised November 28, 2013; accepted December 5, 2013

Copyright (C) 2014 Mohammad Sadiq et al. This is an open access article distributed under the Creative Commons Attribution License, which permits unrestricted use, distribution, and reproduction in any medium, provided the original work is properly cited. In accordance of the Creative Commons Attribution License all Copyrights (C) 2014 are reserved for SCIRP and the owner of the intellectual property Mohammad Sadiq et al. All Copyright (c) 2014 are guarded by law and by SCIRP as a guardian.

\begin{abstract}
Direct aldol reactions have been successfully performed using aromatic aldehyde and cyclic ketone in nonpolar solvent by using immobilized picolylamine on zirconia as a catalyst, in a double walled batch reactor. The prepared catalyst was characterized by SEM, XRD and FT-IR. FT-IR peaks reveal the presence of picolylamine on the surface of zirconia. The catalyst shows excellent catalytic activity in aldol reaction of cyclohexanone with benzaldehyde in cyclohexane giving 2-hydroxyphenylmethylcyclohexanone (55.7\% yield) in 4 hr at $80^{\circ} \mathrm{C}$. Furthermore, the catalyst is recoverable by simple filtration and could be used several times without significant loss in activity.
\end{abstract}

\section{KEYWORDS}

\section{Immobilized Picolylamine on Zirconia; Aldol Reaction; Cyclohexanone; Benzaldehyde}

\section{Introduction}

Aldol reaction catalyzed by proline and picolylamine was extensively investigated for enantioselective carboncarbon bond formation [1-4]. The enantioselectivity of carbon-carbon bond mainly depending on solubility of catalytic material in polar and non-polar solvents such as aldol reaction of cyclohexanone with p-nitrobenzaldehyde catalyzed by proline has high ee\% value in DMSO while failed in water $[3,4]$. To deal with the solubility problem, immobilization of catalytic materials such as proline on solid support may be the most effective method [5-10]. Recently, immobilized proline on silica gel, meso-porous materials and resins for aldol reaction have been reported with modest to excellent enantioselectivity depending on support, substrate and solvent [6-9]. Here we report the immobilized picolylamine on zirconia for aldol reaction of cyclohexanone and benzaldehyde at mild reaction conditions by using different solvent systems.

\section{Experimental}

\subsection{Chemicals}

The reagents used in this study were of high grade and were used without further purification.

\subsection{Zirconia Preparation}

$\mathrm{ZrO}_{2}$ was prepared from octa-hydrated zirconyl chloride ( $\left.\mathrm{ZrOCl} \cdot 8 \mathrm{H}_{2} \mathrm{O}\right)$ by ammonolysis to make the solution basic (pH 9 - 10), which turned the solution to dense precipitate. To remove the traces of chloride ions the precipitate was washed for $24 \mathrm{hr}$ with triple distilled water using a modified Soxhlet's apparatus until the chloride ion test with $\mathrm{AgNO}_{3}$ was negative. The precipitate $\mathrm{Zr}(\mathrm{OH})_{4}$ was dried in oven at $110^{\circ} \mathrm{C}$. The dried zirconia was ground and calcined at $930^{\circ} \mathrm{C}$ in Nabertherm C-19 at a rate of $0.5^{\circ} \mathrm{C} / \mathrm{min}$. Finally dry monoclinic zirconia was achieved and kept in sealed bottle.

\subsection{Synthesis of Picolylamine}

$1.2 \mathrm{~g} \mathrm{NaH}$ in $40 \mathrm{~mL}$ anhydrous toluene at $25^{\circ} \mathrm{C}$ was taken in $250 \mathrm{~mL}$ two neck round bottom flask, $0.32 \mathrm{~g} 18-\mathrm{C}$ 6 and $1.35 \mathrm{~mL}$ acetyl pyridine was added and stirred for $20 \mathrm{~min}$. $3.6 \mathrm{~mL}$ benzyl bromide was added drop wise and stirred at $50^{\circ} \mathrm{C}$ for 6 hours under inert atmosphere to get the desired ketone, 2-Benzyl-3-phenyl-1-(pyridine-2yl) 
propan-1-one. A mixture of 3.33 g hydroxyl ammonium chloride and $6.69 \mathrm{~mL} \mathrm{Et}_{3} \mathrm{~N}$ in $53 \mathrm{~mL}$ ethanol was stirred at room temperature for 30 minutes. 4.82 g 2-Benzyl-3phenyl-1-(pyridine-2yl) propan-1-one was added and reflux for $8 \mathrm{hr}$, the solvent was removed by rotary evaporation and the residue was extracted with EtOAc $(50 \mathrm{~mL}$ $\times 3$ ). The combined organic layers were washed with brine, dried over $\mathrm{Na}_{2} \mathrm{SO}_{4}$ and concentrated to give the crude oxime as brown oil. Without further purification, the crude $5.06 \mathrm{~g}$ oxime was added to $70 \mathrm{~mL}$ ethanol with $1.64 \mathrm{~g} \mathrm{NH}_{4} \mathrm{OAc}$ and $\mathrm{NaOH}\left(59 \mathrm{~mL}, 25 \% \mathrm{v} / \mathrm{v}\right.$ in $\mathrm{H}_{2} \mathrm{O}$ ). This solution was heated at reflux and zinc powder (5.0 equiv, $5.05 \mathrm{~g}, 80.0 \mathrm{mmol}$ ) was added portion wise over 2 hours every $15 \mathrm{~min}$. After refluxing for an additional 8 hours, the reaction mixture was cooled to room temperature and concentrated $\mathrm{NaOH}$ was added until reaching a $\mathrm{pH} \approx 12$. After filtration through celite and washing with diethyl ether, the layers were combined, washed with brine, dried over $\mathrm{Na}_{2} \mathrm{SO}_{4}$, filtered and concentrated. After column chromatography, EtOAc/pet ether (1:4), picolylamine was obtained as pure viscous oil.<smiles>NC(c1ccccn1)C(CP)CP</smiles>

2-benzyl-3-phenyl-1-(pyridine-2yl)propan-1-amine

\subsection{Immobilized Picolylamine on $\mathrm{ZrO}_{2}$}

$0.1 \mathrm{~g}$ of picolylamine was dissolved in $50 \mathrm{~mL}$ of toluene. $4.9 \mathrm{~g}$ of zirconia was added to it. The mixture was sonicated for 30 min that uniform adsorption takes place on the surface of zirconia. Then the solvent was completely evaporated. The dried catalyst was obtained and kept in a sealed bottle.

\subsection{Characterization of the Catalyst}

Modern techniques such as XRD, SEM and FTIR were used for characterization of the catalyst. SEM micrographs were recorded on $30 \mathrm{KV}$ Scanning Electron Microscope (JSM 5910, JEOL, Japan), diffractograms were recorded on X-ray differactrometerRigaku D/Max-II, Cu tube, Japan with a tube voltage of $40 \mathrm{KV}$ and $20 \mathrm{~mA}$ and Diffuse reflectance spectra of solids (Zirconia, immobilized picolylamine on zirconia) were recorded on Shimadzu, IRPrestigue-21, FTIR-8400S, using diffuse reflectance accessory [DRS-8000A]. Solid samples were diluted with $\mathrm{KBr}$ before measurement. The spectra were recorded with resolution of $4 \mathrm{~cm}^{-1}$ with 50 accumulations.

\subsection{Test of Prepared Catalyst}

$10 \mathrm{~mL}$ cyclohexanone, $13 \mathrm{~mL}$ benzaldehyde, solvent (water, methanol/water, cyclohexane), catalyst $0.1 \mathrm{~g}$ were loaded to double walled batch reactor equipped with quick fit thermometer and a condenser. The reaction mixture was stirred with magnetic stirrer while temperature of reaction mixture was maintained at $80^{\circ} \mathrm{C}$ for desired reaction durations. The reaction mixture was filtered and dissolved in n-hexane and monitored by (TLC) using silica gel $60 \mathrm{~F}_{254}$ and visualized by UV at $254 \mathrm{~nm}$, FTIR, GC and finally scanned for determination of $\lambda_{\max }$ using UV spectrophotometer (UV 1800). The peaks of FTIR and UV confirmed the desired product formation.

\section{Results and Discussion}

\subsection{Catalyst Characterization}

The SEM images of zirconia and immobilized picolylamine on zirconia show similar smooth morphology as shown in Figure 1. Zirconia and immobilized picolylamine on zirconia have the same particle size (50 - 140 $\mu \mathrm{m})$ calculated by intercept method from SEM images. Figure 2 show XRD pattern of both catalysts which reveal the same intense peaks at $2 \theta=28^{\circ}$ and $2 \theta=31.4^{\circ}$ which is responsible for monoclinic phase while particle size was calculated by Scherrer's equation from XRD

$$
d=\frac{B \lambda}{\beta \cos \theta}
$$

where $\boldsymbol{d}$ is the average particle size of the phase under investigation, $B$ is Scherrer's constant (0.89), $\lambda$ is the wavelength used (1.5405 $\AA$ ), $b$ is the width at mean height of the diffraction peak. The particle size calculated $(124 \mu \mathrm{m})$ from XRD was comparable with particle size calculated from SEM images. SEM and XRD results show that immobilization of picolylamine on zirconia did not alter any change in the structural morphology of zirconia. The XRD of used zirconia show two types of trends as shown in Figure 3. The immobilized picolylamine on zirconia used for the aldol reaction of cyclohexanone with benzaldehyde in solvent (cyclohexane) show no apparent change in morphology (SEM) and crystal structure (XRD). While immobilized picolylamine on zirconia used for the same reaction in solvent methanol/ water and/or water show huge changes in SEM and XRD. The SEM images show that the smooth morphology of zirconia was destroyed while XRD pattern shows that the crystal phase of zirconia also changed. FT-IR spectra of zirconia and immobilized picolylamine on zirconia were given in Figure 4. FT-IR spectral peaks at $3430 \mathrm{~nm}$ and $2980 \mathrm{~nm}$ show that picolylamine was immobilized on the surface of zirconia.

\subsection{Catalytic Test}

Immobilized picolylamine on zirconia was tested in aldol reaction of cyclohexanone $(10 \mathrm{~mL})$ with benzaldehyde 
$(13 \mathrm{~mL})$ in cyclohexane $(10 \mathrm{~mL})$ at $80^{\circ} \mathrm{C}$ and obtained good yield of 2-hydroxy methyl phenyl cyclohexanone in $4 \mathrm{hr}$ as shown in Scheme 1. The reaction was periodically monitored by TLC $\left(60 \mathrm{~F}_{254}\right)$ and visualized under UV light. The product was analyzed by UV spectrophotometer and FT-IR. UV spectrum at $384 \mathrm{~nm}$ and FT-IR spectral peaks at $1690 \mathrm{~nm}$ and $3400 \mathrm{~nm}$ confirm the products 2-hydroxy methyl phenyl cyclohexanone as shown in Figure 5.

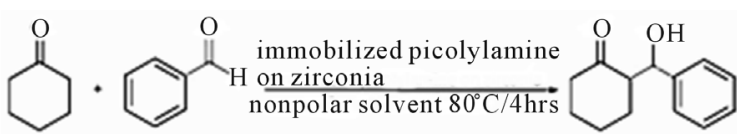

Scheme 1. Aldol reaction of cyclohexanone with benzaldehyde catalyzed by immobilized picolylamine on zirconia to yield 2-hydroxy methyl phenyl cyclohexanone.

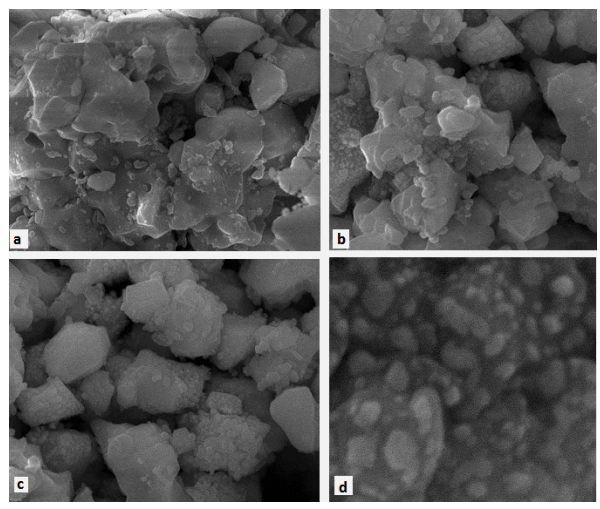

Figure 1. (a) Fresh zirconia calcined at $950^{\circ} \mathrm{C}$, (b) Immobilized picolylamine on zirconia, (c) Immobilized picolylamine on zirconia used in aldol reaction of cyclohexanone with benzaldehyde in nonpolar solvent at $80^{\circ} \mathrm{C}$ for $240 \mathrm{~min}$, (d) Immobilized picolylamine on zirconia used in aldol reaction of cyclohexanone with benzaldehyde in polar solvent at $80^{\circ} \mathrm{C}$ for $240 \mathrm{~min}$.

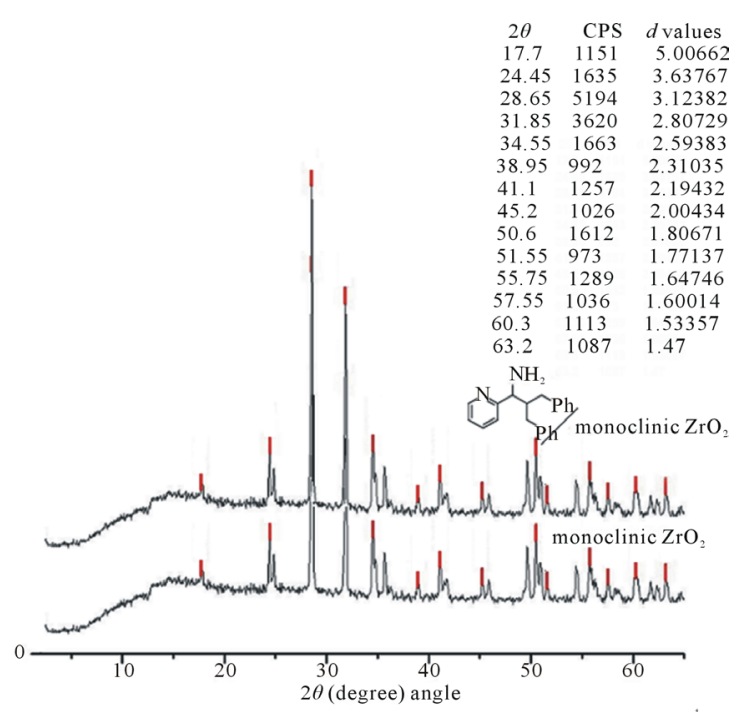

Figure 2. XRD patterns of monoclinic zirconia and immobilized picolylamine on zirconia.

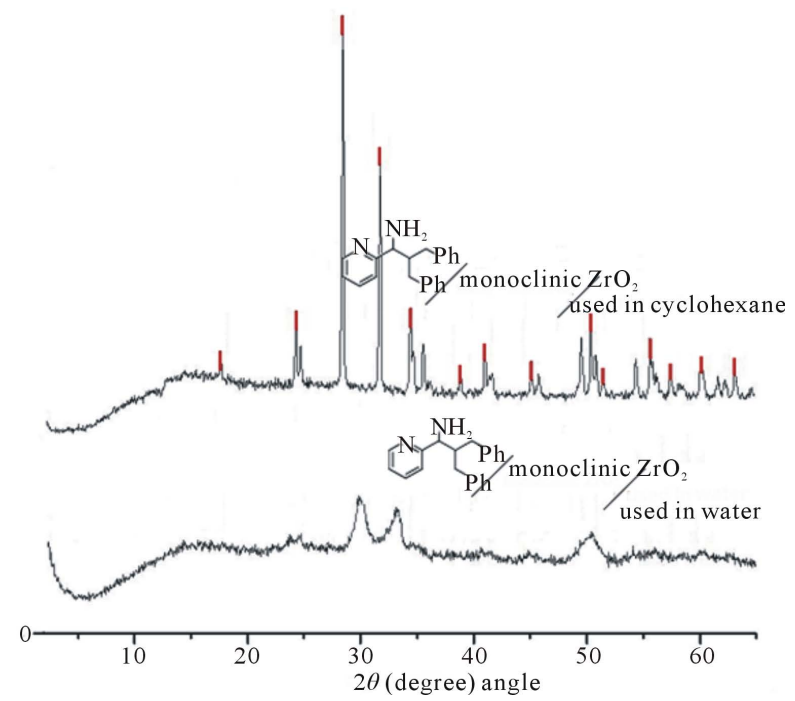

Figure 3. XRD patterns of immobilized picolylamine on zirconia used in aldol reaction of cyclohexanone with benzaldehyde in nonpolar solvent at $80^{\circ} \mathrm{C}$ for $240 \mathrm{~min}$.

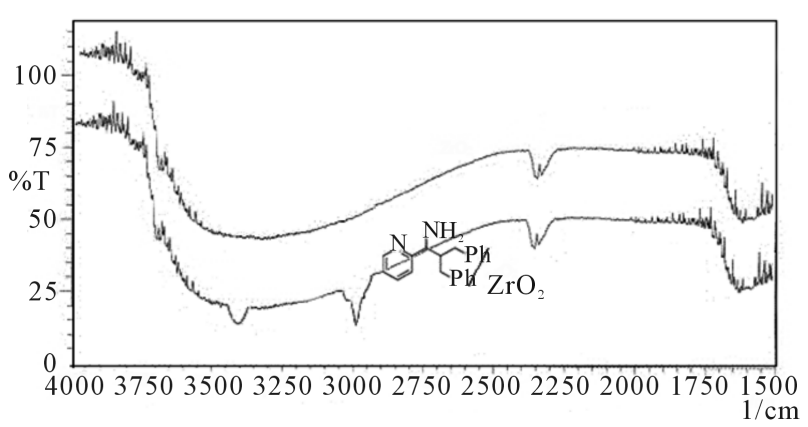

Figure 4. FT-IR spectra of zirconia calcined at $950^{\circ} \mathrm{C}$ and immobilized picolylamine on the surface of monoclinic zirconia.

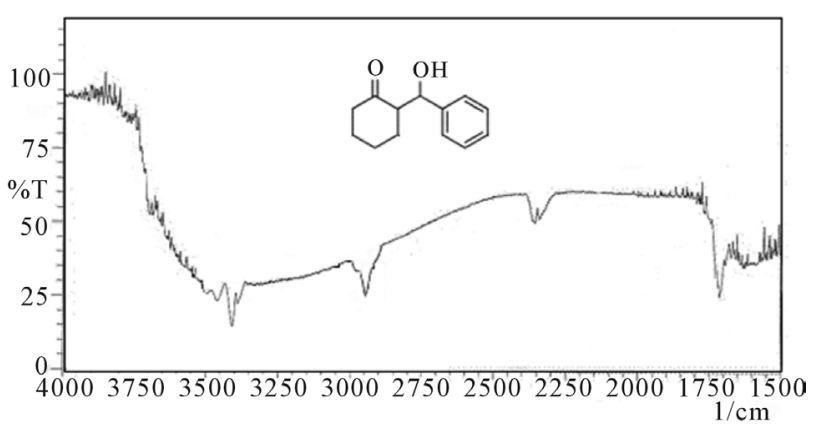

Figure 5. FT-IR of 2-hydroxy methyl phenyl cyclohexanone on the surface of $(0.1 \mathrm{~g})$ immobilized picolylamine on zirconia after being used for the reaction of cyclohexanone with benzaldehyde in nonpolar solvent at $80^{\circ} \mathrm{C}$.

\subsection{Effect of Different Reaction Parameters}

The proposed model aldol reaction of cyclohexanone with benzaldehyde was carried out under different reaction parameters. Experimental observation unveils the 
effects of different reaction parameters on the rate of reaction.

\subsubsection{Time Profile Study}

Figure 6 shows the effect of time on \% yield. The time profile studies reflect that the \% conversion increases with increase in reaction duration. The reactions were performed for $60 \mathrm{~min}, 120 \mathrm{~min}, 180 \mathrm{~min}$ and $240 \mathrm{~min}$ while keeping other condition as cyclohexanone $10 \mathrm{~mL}$, benzaldehyde $13 \mathrm{~mL}$, cyclohexane $10 \mathrm{~mL}$, catalyst $0.1 \mathrm{~g}$, temperature $80^{\circ} \mathrm{C}$ and stirring $900 \mathrm{rpm}$. Increase in the yield pointing the fact that the contact time of the catalyst with the reactants directly affects the rate of reaction.

\subsubsection{Solvent Effect}

The solvents played an important role in the reaction [4-7]. Non Polar solvents showed better results than polar solvents. In the presence of immobilized picolylamine on zirconia $(0.1 \mathrm{~g})$, when the reaction was performed in cyclohexane (as solvent and reactant in some case), good yield of desired product was obtained. However, other solvents such as methanol $/ \mathrm{H}_{2} \mathrm{O}(\% \mathrm{~V} / \mathrm{V}, 50 / 50)$, were substantially less effective or no reaction at all in water. In our case the prominent reason is deformation of zirconia structure or change of crystal phase as shown in Figure 3.

\subsubsection{Temperature Effect}

The effect of the reaction temperature was also investigated in aldol reaction of cyclohexanone with benzaldehyde in cyclohexane for different durations using immobilized picolylamine on zirconia. At temperature $\left(60^{\circ} \mathrm{C}\right)$, the reaction took place smoothly with good yield. A slightly higher yield was obtained when the reaction was performed at $80^{\circ} \mathrm{C}$. It is interesting to observe that conversion was maintained when $0.1 \mathrm{~g}$ of zirconia-supported catalyst was added to the reactions at $80^{\circ} \mathrm{C}$ but decreases when temperature further increases. Activation energy ( $E a=71.5 \mathrm{~kJ} / \mathrm{mol}$ ) was calculated using Arhenius equation $(\ln k=\ln A-E a / R T)$ as shown in Figure 7.

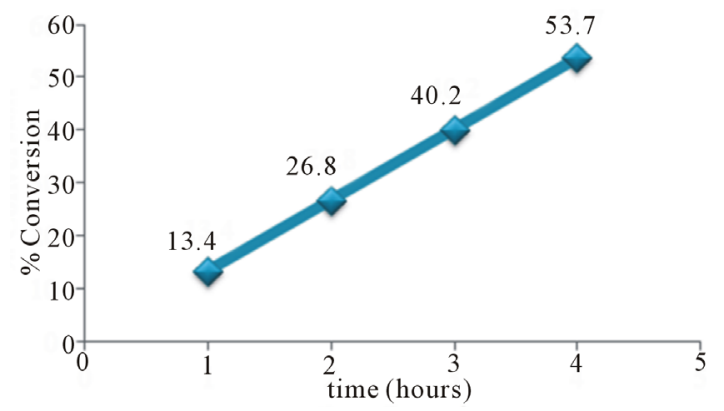

Figure 6. Plot of Time (hours) vs. \% Conversion; aldol reaction of cyclohexanone with benzaldehyde in cyclohexane catalyzed by immobilized picolylamine on zirconia at $80^{\circ} \mathrm{C}$.

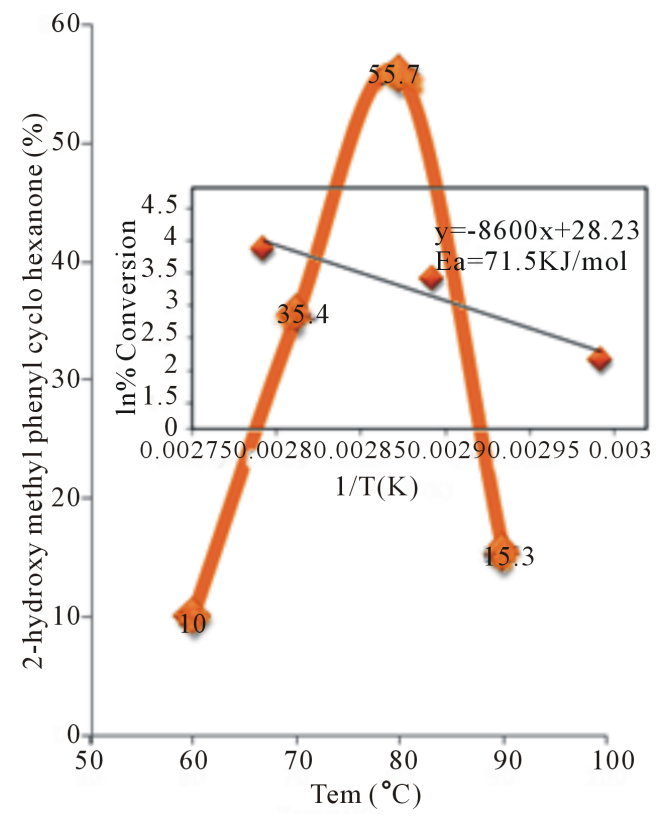

Figure 7. Effect of temperature (activation energy $\mathbf{k J} / \mathrm{mol}$ ) on \% yield in aldol reaction of cyclohexanone with benzaldehyde in nonpolar solvent for $240 \mathrm{~min}$ using immobilized picolylamine on zirconia.

\subsubsection{Life Span of the Catalyst}

To study the recyclability of immobilized picolylamine on zirconia, a more practical method was applied to the reaction between cyclohexanone with benzaldehyde in nonpolar solvent at $80^{\circ} \mathrm{C}$ for $240 \mathrm{~min}$. When cyclohexanone was treated with aldehyde with $(0.1 \mathrm{~g})$ catalyst loading at $80^{\circ} \mathrm{C}$ for $240 \mathrm{~min}$, the desired aldol product was obtained in $55.7 \%$ yield. After carrying out a reaction, isolating the product from the reaction mixture, washing with solvents, drying and recovering catalyst and fresh starting materials were charged into the reaction system. The reactions still proceeded well. Catalyst underwent five repetitive cycles with only minor decreases in product yields.

\section{Conclusions}

In the recent years, organocatalysis has been extensively investigated for high yield and enantioselectivity. But still extensive research was needed to address the problems like high enantioselectivity for a narrow range of substrates and use of large amount of catalysts. The picolylamine used in this study was already used efficiently for aldol reactions in polar and nonpolar solvents with high yield and ee\% values but still the problems of homogeneous catalysis like recovery of the catalyst from reaction mixture, large amount loading of catalyst in the reaction made it impractical for industries. So here we report highly efficient organocatalyst (immobilized picolylamine on zirconia) for aldol reaction of cyclohexanone with benzaldehyde in nonpolar solvent (cyclohex- 
ane) and obtain 55.7\% yield of 2-hydroxy methyl phenyl cyclohexanone at $80^{\circ} \mathrm{C}$ in $4 \mathrm{hr}$. The catalyst behaves like a truly heterogeneous catalyst. It was easy to recover from reaction mixture by simple filtration and reused many times with sustainable activity. The reason why the catalyst system is feasible and affordable is that it has broad substrate applicability, low catalyst loading and extended life span. The present research will open new ways in the field of organocatalysis.

Prospective of the research: the racemic picolylamine was resolved into (R)-picolylamine with (S, S)-Dtartaric acid. Immobilized (R)-picolylamine on zirconia was used for aldol reaction of cyclohexanone with benzaldehyde in the same reaction condition. The preliminary results show high \% yield with every high ee value, 93\%. The research is in progress and the data will be published in near future.

\section{Acknowledgements}

The authors gratefully acknowledge financial support of Higher Education Commission of Pakistan (Project No: 20-1604/R\&D/092198) and Pakistan Science Foundation (Project No.PSF/Res/F-UM/Chem-434).

\section{REFERENCES}

[1] Modern Aldol Reactions, Vols. 1 \& 2 (Ed.:R. Mahrwald), Wiley-VCH, Weinheim 2004.

[2] B. List, R. A. Lerner and C. F. Barbas III, "Proline-Catalyzed Direct Asymmetric Aldol Reactions,” Journal of the American Chemical Society, Vol. 122, No. 10, 2000, pp. 2395-2396. http://dx.doi.org/10.1021/ja994280y

[3] B. List, "Proline-Catalyzed Asymmetric Reactions," Te- trahedron, Vol. 58, No. 28, 2002, pp. 5573-5590. http://dx.doi.org/10.1016/S0040-4020(02)00516-1

[4] E. R. Jarvo and S. J. Miller, "Amino Acids and Peptides as Asymmetric Organo Catalysts,” Tetrahedron, Vol. 58, No. 13, 2002, pp. 2481-2495. http://dx.doi.org/10.1016/S0040-4020(02)00122-9

[5] W. Notz, F. Tanaka and C. F. Barbas III, "EnamineBased Organocatalysis with Proline and Diamines: The Development of Direct Catalytic Asymmetric Aldol, Mannich, and Diels-Alder Reactions," Accounts of Chemical Research, Vol. 37, No. 8, 2004, pp. 580-591. http://dx.doi.org/10.1021/ar0300468

[6] N. Mase, Y. Nakai, N. Ohara, H. Yoda, K. Takabe, F. Tanaka and C. F. Barbas, "Organocatalytic Direct Asymmetric Aldol Reactions," Journal of the American Chemical Society, Vol. 128, No. 3, 2006, pp. 734-735. http://dx.doi.org/10.1021/ja0573312

[7] Y. Hayashi, "In Water or in the Presence of Water?" Angewandte Chemie International Edition, Vol. 45, No. 48, 2006, pp. 8103-8104. http://dx.doi.org/10.1002/anie.200603378

[8] F. Cozzi, "Immobilization of Organic Catalysts," Advanced Synthesis \& Catalysis, Vol. 348, No. 12-13, 2006, pp. 1367-1390. http://dx.doi.org/10.1002/adsc.200606096

[9] M. Benaglia, A. Puglisi and F. Cozzi, "Polymer-Supported Organic Catalysts,” Chemical Reviews, Vol. 103, No. 9, 2003, pp. 3401-34029. http://dx.doi.org/10.1021/cr010440o

[10] A. Corma and H. Garcia, "Silica-Bound Homogenous Catalysts as Recoverable and Reusable Catalysts in Organic Synthesis,” Advanced Synthesis \& Catalysis, Vol. 348, No. 12-13, 2006, pp. 1391-1412. http://dx.doi.org/10.1002/adsc.200606192 